\title{
Metachronous testicular seminoma occurring 8 years after treatment of extragonadal nonseminomatous germ cell tumor in the retroperitoneum
}

\author{
Kosuke Shibamori $\cdot$ Toshiaki Tanaka $\cdot$ \\ Hiroshi Kitamura Naoya Masumori • \\ Taiji Tsukamoto
}

Received: 1 October 2012/Accepted: 22 November 2012/Published online: 20 December 2012

(C) The Japan Society of Clinical Oncology 2012

\begin{abstract}
We report a case of metachronous testicular seminoma occurring 8 years after treatment of extragonadal nonseminomatous germ cell tumor in the retroperitoneum. A 29-year-old male Japanese patient presented with a bulky tumor in the left obturator fossa. The serum levels of alfafetoprotein and lactate dehydrogenase were extremely high. He underwent open tumor biopsy and the pathological finding was immature teratoma. After three cycles of BEP therapy (bleomycin, etoposide, cisplatin), we performed retroperitoneal lymph node dissection and tumor resection. We added one cycle of VIP therapy (vinblastine, ifosfamide, cisplatin) as a salvage therapy because the pathological examination demonstrated immature teratoma with suspicious viable germ cell tumors. Eight years after surgery, the patient noticed that the left testis was swollen. All tumor markers were within normal limits. We performed a left radical orchiectomy, and pathological examination revealed pure seminoma with invasion of the rete testis. We emphasize the necessity of self-examination after treatment of extragonadal germ cell tumor.
\end{abstract}

Keywords EGGCT $\cdot$ Metachronous - Seminoma · Germ cell tumor

\section{Introduction}

Extragonadal germ cell tumor (EGGCT) is rare and accounts for 2-5\% of cancer diagnosis in all germ cell

K. Shibamori $(\bowtie) \cdot$ T. Tanaka $\cdot$ H. Kitamura $\cdot$ N. Masumori ·

T. Tsukamoto

Department of Urology, Sapporo Medical University School

of Medicine, S1W16, Chuo-ku, Sapporo 064-8543, Japan

e-mail: shibamori.k@gmail.com tumors [1]. Metachronous testicular tumor after EGGCT is also rare. To the best of our knowledge, 35 cases were reported in the literature [2-14]. Herein we report a case of metachronous testicular pure seminoma occurring 8 years after treatment of immature teratoma in the pelvis.

\section{Case report}

The patient was previously reported as a case with EGGCT arising in an unusual site [15]. He noticed left inguinal and hip pain at the age of 29 years old. Magnetic resonance imaging (MRI) showed a bulky tumor in the left obturator fossa (Fig. 1). The size of the tumor was $10 \times 6 \times$ $10.5 \mathrm{~cm}$, and the para-aortic lymph node was also swollen $(4 \times 3 \mathrm{~cm})$. Serum levels of AFP (alpha-fetoprotein) and LDH (lactate dehydrogenase) were extremely high (12946.2 $\mathrm{ng} / \mathrm{ml}$ and $508 \mathrm{IU} / \mathrm{L}$, respectively). On the other hand, the serum level of beta human chorionic gonadotropin was within the normal limits.

Open tumor biopsy revealed it was immature teratoma (Fig. 2). Radiographic and physical examination revealed no abnormal findings in the bilateral testes, including burnout tumor. After three cycles of BEP therapy (bleomycin, etoposide, cisplatin) and normalization of tumor markers, we performed retroperitoneal lymph node dissection and tumor resection. The pathological examination demonstrated immature teratoma with suspicious viable germ cell tumors, and the main tumor was located in an extralymphatic site. Then we added one cycle of VIP therapy (vinblastine, ifosfamide, cisplatin) as a salvage therapy.

There had been no findings suggestive of recurrence and metastasis after the initial treatment. Eight years after surgery, however, the patient noticed the left testis swollen without scrotal pain. The size of left testis was $5.5 \times 3.2 \mathrm{~cm}$, 


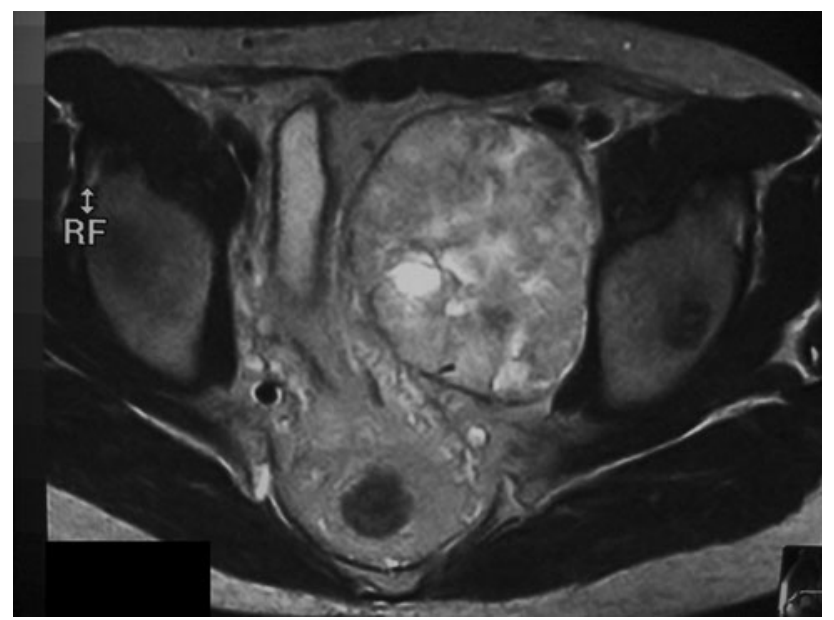

Fig. 1 MRI findings before BEP therapy. There was a solid, bulky tumor $(10 \times 6 \mathrm{~cm})$ in the pelvis with a heterogeneous area

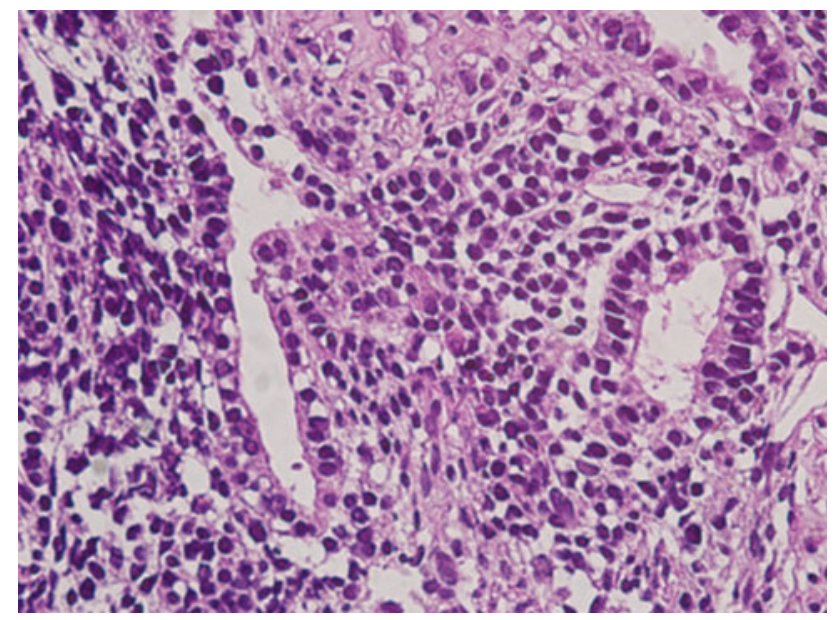

Fig. 2 Macroscopic findings of pelvic tumor show mature and immature ductal structure composed of columnar epithelium and squamous epithelium

and ultrasonography showed a heterogeneous solid mass. There was no abnormal finding in the right testis and no radiographic evidence of metastatic disease. All tumor markers were within normal limits. We performed a left radical orchiectomy, and pathological examination revealed pure seminoma with invasion of the rete testis (Fig. 3). After that, we added two cycles of carboplatin as adjuvant chemotherapy because we decided he was at high risk of developing recurrence. He was free from disease 10 months after surgery.

\section{Discussion}

Metachronous testicular tumor after EGGCT is rare. To the best of our knowledge, 35 cases were reported in the

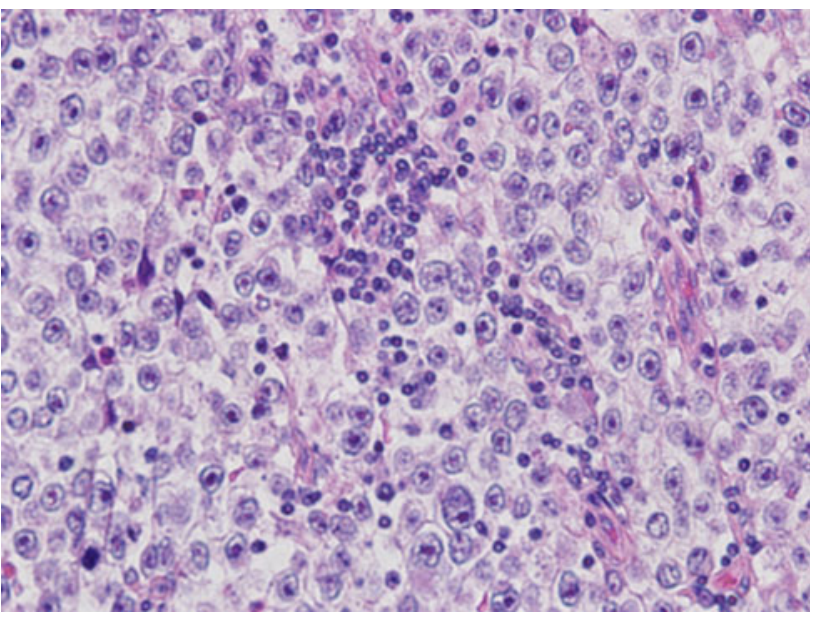

Fig. 3 Macroscopic findings of metachronous testicular tumor show clear cytoplasm with big nuclei and infiltration by lymphocytes, i.e., pure seminoma

literature, as summarized in Table 1 [2-14]. Hartmann et al. [8] reported that the cumulative risk for development of metachronous testicular cancer 10 years after diagnosis of EGGCT is $10.3 \%$. Also they reported that metachronous testicular cancer occurred in $14.2 \%$ of retroperitoneal EGGCT and $6.2 \%$ of mediastinal EGGCT cases. The cumulative risk of seminomatous EGGCT was $1.4 \%$, whereas that of nonseminomatous EGGCT was $14.3 \%$.

It is controversial whether EGGCT is a primary tumor or metastasis of testicular intraepithelial neoplasia (TIN). We did not perform testis biopsy when he developed EGGCT. He might have had TIN in the left testis and presented with a late relapse this time. In our patient, however, microscopic examination revealed that the tumor in the pelvis grew outside the lymphatic tissue, whereas the left obturator lymph node did not contain the tumor tissue. This finding suggested that the pelvic tumor was of extragonadal origin rather than the result of lymph node metastasis. Therefore, we concluded that the testicular seminoma was a metachronous tumor.

Interestingly, the combination of nonseminomatous EGGCT and metachronous seminoma, similar to our case, was the most common in the reported cases. The mechanism of the trend to develop this combination is unclear. Oosterhuis et al. $[16,17]$ showed that the primitive germ cell tumor could differentiate into seminoma, and seminoma could differentiate into nonseminoma in stages. We hypothesized that EGGCT would be asymptomatic until it grew bulky because of its development deep in the body, so that it would tend to differentiate into nonseminoma at the time of diagnosis. On the other hand, MTT would be detected more easily in the early period because it is palpable in the scrotum and would be noticed in the follow-up for EGGCT. 
Table 1 Summary of reported cases of EGGCT with metachronous testicular tumor

\begin{tabular}{|c|c|c|c|c|c|c|c|c|c|c|}
\hline No. & Author & $\begin{array}{l}\text { Years of } \\
\text { publication }\end{array}$ & Age & $\begin{array}{l}\text { Primary } \\
\text { site of } \\
\text { EGGCT }\end{array}$ & $\begin{array}{l}\text { EGGCT } \\
\text { histology }\end{array}$ & $\begin{array}{l}\text { MTT } \\
\text { histology }\end{array}$ & $\begin{array}{l}\text { Elevated } \\
\text { markers } \\
(\text { EGGCT) }\end{array}$ & $\begin{array}{l}\text { Elevated } \\
\text { markers } \\
(\mathrm{MTT})\end{array}$ & $\begin{array}{l}\text { Interval } \\
\text { between } \\
\text { EGGCT } \\
\text { and MTT }\end{array}$ & $\begin{array}{l}\text { follow up } \\
\text { period after } \\
\text { diagnosis } \\
\text { of MTT }\end{array}$ \\
\hline 1 & Quintela AG & 1991 & 44 & $\mathrm{rp}$ & Sem & Non-sem & $\mathrm{LDH}, \beta-\mathrm{hCG}$ & AFP & 7 yrs. & 3 yrs. \\
\hline 2 & Lokich J & 1994 & 22 & $\mathrm{rp}$ & Non-sem & Sem & normal & normal & $14 \mathrm{yrs}$. & unknown \\
\hline 3 & Hayashi T & 1996 & 18 & unknown & Non-sem & Sem & LDH, AFP & $\mathrm{LDH}, \beta-\mathrm{hCG}$ & 7 yrs. & unknown \\
\hline 4 & Gerl A & 1996 & Unknown & $\mathrm{rp}$ & Non-sem & Sem & Unknown & Unknown & 35 mo. & $30 \mathrm{mo}$. \\
\hline 5 & Gerl A & 1996 & Unknown & $\mathrm{rp}$ & Non-sem & Sem & Unknown & Unknown & 42 mo. & 49 mo. \\
\hline 6 & Gerl A & 1996 & Unknown & $\mathrm{rp}$ & Non-sem & Sem & Unknown & Unknown & 77 mo. & $106 \mathrm{mo}$. \\
\hline 7 & Allaway M & 2000 & 22 & unknown & Non-sem & Sem & AFP & normal & 7 yrs. & $30 \mathrm{mo}$. \\
\hline 8 & Daniel C & 2001 & 24 & $\mathrm{rp}$ & Sem & Non-sem & $\beta$-hCG & hCG & 5 yrs. & 7 yrs. \\
\hline 9 & Daniel C & 2001 & 23 & $\mathrm{rp}$ & Non-sem & Non-sem & Unknown & normal & $23 \mathrm{mo}$ & $10 \mathrm{yrs}$. \\
\hline 10 & Hartmann JT & 2001 & 28 & $\mathrm{rp}$ & Non-sem & Sem & $\beta$-hCG & Unknown & 74 mo. & $51 \mathrm{mo.}$ \\
\hline 11 & Hartmann JT & 2001 & 19 & med & Non-sem & Sem & AFP, $\beta$-hCG & Unknown & 80 mo. & 35 mo. \\
\hline 12 & Hartmann JT & 2001 & 33 & $\mathrm{rp}$ & Non-sem & Non-sem & AFP, $\beta$-hCG & Unknown & 30 mo. & 40 mo. \\
\hline 13 & Hartmann JT & 2001 & 40 & $\mathrm{rp}$ & Non-sem & Sem & normal & Unknown & $100 \mathrm{mo}$. & $66 \mathrm{mo.}$ \\
\hline 14 & Hartmann JT & 2001 & 49 & $\mathrm{rp}$ & Non-sem & Sem & normal & Unknown & 88 mo. & 115 mo. \\
\hline 15 & Hartmann JT & 2001 & 24 & med & Sem & Non-sem & $\beta$-hCG & Unknown & 41 mo. & $51 \mathrm{mo}$. \\
\hline 16 & Hartmann JT & 2001 & 29 & $\mathrm{rp}$ & Non-sem & Non-sem & AFP, $\beta$-hCG & Unknown & 30 mo. & $102 \mathrm{mo}$. \\
\hline 17 & Hartmann JT & 2001 & 22 & $\mathrm{rp}$ & Non-sem & Sem & AFP & Unknown & 48 mo. & 4 mo. \\
\hline 18 & Hartmann JT & 2001 & 23 & $\mathrm{rp}$ & Non-sem & Sem & AFP & Unknown & 14 mo. & 74 mo. \\
\hline 19 & Hartmann JT & 2001 & 26 & med & Non-sem & Non-sem & AFP, $\beta$-hCG & Unknown & 84 mo. & $18 \mathrm{mo.}$ \\
\hline 20 & Hartmann JT & 2001 & 48 & med & Non-sem & Sem & normal & Unknown & 72 mo. & $1 \mathrm{mo}$ \\
\hline 21 & Hartmann JT & 2001 & 34 & $\mathrm{rp}$ & Non-sem & Sem & AFP, $\beta$-hCG & Unknown & 35 mo. & $68 \mathrm{mo.}$ \\
\hline 22 & Hartmann JT & 2001 & Unknown & $\mathrm{rp}$ & Non-sem & Sem & AFP & Unknown & $102 \mathrm{mo}$. & 22 mo. \\
\hline 23 & Hartmann JT & 2001 & 30 & $\mathrm{rp}$ & Non-sem & Sem & normal & Unknown & 42 mo. & $153 \mathrm{mo}$. \\
\hline 24 & Hartmann JT & 2001 & 34 & $\mathrm{rp}$ & Non-sem & Sem & normal & Unknown & $78 \mathrm{mo}$. & $108 \mathrm{mo}$. \\
\hline 25 & Hartmann JT & 2001 & 22 & $\mathrm{rp}$ & Non-sem & Non-sem & $\beta$-hCG & Unknown & 39 mo. & $7 \mathrm{mo.}$ \\
\hline 26 & Mindrup SR & 2004 & 42 & & Non-sem & Non-sem & $\begin{array}{l}\text { AFP, } \beta \text {-hCG, } \\
\text { LDH }\end{array}$ & normal & $50 \mathrm{mo}$. & unknown \\
\hline 27 & Kuroda & 2004 & 32 & $\mathrm{rp}$ & Non-sem & Sem & normal & normal & 4 yrs. & unknown \\
\hline 28 & Ando & 2007 & 22 & unknown & Non-sem & Sem & $\beta$-hCG, LDH & normal & 8 yrs. & $6 \mathrm{mo}$ \\
\hline 29 & Yamada & 2008 & 30 & $\mathrm{rp}$ & unknown & Sem & $\begin{array}{l}\text { AFP, } \beta-\mathrm{hCG} \text {, } \\
\text { LDH, } \\
\text { DUPAN2 } \\
\text { CA19-9 }\end{array}$ & $\begin{array}{l}\text { LDH, } \\
\beta-h C G\end{array}$ & 8 yrs. & $15 \mathrm{mo.}$ \\
\hline 30 & Kawamura & 2009 & 33 & $\mathrm{rp}$ & Sem & Non-sem & normal & LDH, HCG & 8 yrs. & $10 \mathrm{mo}$. \\
\hline 31 & Hashimoto & 2010 & 27 & $\mathrm{rp}$ & Non-sem & Sem & Unknown & HCG & $120 \mathrm{mo}$. & 4 mo. \\
\hline 32 & Hashimoto & 2010 & 30 & $\mathrm{rp}$ & Sem & Non-sem & Unknown & $\mathrm{HCG}$ & 96 mo. & $30 \mathrm{mo}$. \\
\hline 33 & Hashimoto & 2010 & 28 & $\mathrm{rp}$ & Non-sem & Sem & Unknown & HCG & 64 mo. & $16 \mathrm{mo}$. \\
\hline 34 & Hashimoto & 2010 & 32 & $\mathrm{rp}$ & Non-sem & Sem & Unknown & HCG & 15 mo. & $30 \mathrm{mo}$. \\
\hline 35 & Hashimoto & 2010 & 47 & $\mathrm{rp}$ & Non-sem & Non-sem & Unknown & HCG & $21 \mathrm{mo}$ & 4 mo. \\
\hline 36 & Present case & 2012 & 29 & $\mathrm{rp}$ & Non-sem & Sem & AFP, LDH & normal & 8 yrs. & $10 \mathrm{mo}$. \\
\hline
\end{tabular}

Age age at EGGCT diagnosis, EGGCT extra gonadal germ cell tumor, MTT metachronous testicular tumor, Sem seminoma, Non-sem nonseminoma, $L D H$ lactate dehydrogenase, $H C G$ human chorionic gonadotropin, $\beta$ - $h C G$ human $\beta$-chorionic gonadotropin, $A F P \alpha$-fetoprotein, CA19-9 carbohydrate antigen $19-9, r p$ retroperitoneum, med mediastinum, yrs years 
In this case, although serum AFP levels were extremely elevated, open biopsy revealed no component other than immature teratoma. The tumor possibly had components of embryonal carcinoma or a yolk sac tumor that were not detected by sampling. Furthermore, the necessity for an appropriate regimen of salvage chemotherapy for patients with immature teratoma only proven in the residual mass had not been established at that time. Recently, two cycles of cisplatin-based chemotherapy were recommended for patients with proven viable cancer cells or immature teratoma found by residual mass resection [18]. However, the number of cycles was determined empirically [19] and is not well validated. Although we performed only one cycle of VIP therapy, the treatment strategy may not have affected the metachronous recurrence in this case.

Given that patients with germ cell tumors have a high risk of metachronous testicular tumor [8], we emphasize the necessity of self-examination of the testes as well as long-term follow-up with both physical and tumor marker examinations by medical doctors after treatment of EGGCT.

Conflict of interest The authors declare that they have no conflict of interest.

\section{References}

1. Bokemeyer C, Nichols CR, Droz JP et al (2002) Extragonadal germ cell tumors of the mediastinum and retroperitoneum: results from an international analysis. J Clin Oncol 20:1864-1873

2. Quintela AG, Bonet EL, Roman L et al (1991) Testicular germ cell tumor seven years after a retroperitoneal germ cell tumor. Eur Urol 19:336-338

3. Lokich J (1994) Metachronous gonadal and extragonadal primary germ cell tumors: two case reports. Cancer Invest 12:406-408

4. Hayashi T, Mine M, Kojima S et al (1996) Extragonadal germ cell tumor followed by metachronous testicular tumor. Urol Int 57:194-196

5. Gerl A, Clemm C, Lamerz R et al (1996) Cisplatin-based chemotherapy of primary extragonadal germ cell tumors. A single institution experience. Cancer 77:526-532
6. Allaway M, Nseyo UO (2000) Primary testicular seminoma in a patient with a history of extragonadal non-seminomatous germ cell carcinoma. Urology 55:949-950

7. Daniel C, Fizazi K, Culine S et al (2001) Metachronous gonadal and extragonadal primaries, or late relapse of germ cell tumor? Urol Oncol 6:49-52

8. Hartmann JT, Fossa SD, Nichols CR et al (2001) Incidence of metachronous testicular cancer in patients with extragonadal germ cell tumors. J Natl Cancer Inst 93:1733-1738

9. Mindrup SR, Konety BR (2004) Testicular recurrence from "primary" retroperitoneal germ cell tumor. Urology 64:10311032

10. Kuroda I, Ueno M, Mitsuhashi T et al (2004) Testicular seminoma after the complete remission of extragonadal yolk sac tumor: a case report. BMC Urol 4:13

11. Ando R, Yasui T, Tozawa K et al (2007) Testicular seminoma occurring 8 years after treatment of a metastatic extragonadal germ cell tumor. Int J Urol 14:85-86

12. Yamada Y, Tomita K, Fujimura T et al (2008) Metachronous testicular tumor developing eight years after retroperitoneal extragonadal germ cell tumor. Int J Urol 15:267-269

13. Kawamura N, Yamamoto K, Yoshioka I et al (2009) A case of metachronous testicular tumor developing seven years after complete remission of retroperitoneal extragonadal germ cell tumor. Hinyokika kiyo 55:635-638

14. Hashimoto K, Fujimoto H, Kouno T et al (2012) The incidence and management of metachronous testicular germ cell tumors in patients with extragonadal germ cell tumors. Urol Oncol 30:319324

15. Tanaka T, Kitamura H, Masumori N et al (2006) Retroperitoneal extragonadal germ cell tumor presenting as a bulky pelvic mass of the obturator fossa. Int J Urol 13:180-182

16. Oosterhuis JW, Castedo SM, de Jong B et al (1989) Ploidy of primary germ cell tumors of the testis: pathogenetic and clinical relevance. Lab Invest 60:14-20

17. Oosterhuis JW, Looijenga LH (2003) Current views on the pathogenesis of testicular germ cell tumors and perspectives for future research: highlights of the 5th Copenhagen workshop on carcinoma in situ and cancer of the testis. APMIS 111:280-289

18. Albers P, Albrecht W, Algaba F et al (2011) EAU guidelines on testicular cancer: 2011 update. Eur Urol 60:304-319

19. Fizazi K, Tjulandin S, Salvioni R et al (2001) Viable malignant cells after primary chemotherapy for disseminated nonseminomatous germ cell tumors: prognostic factors and role of postsurgery chemotherapy-results from an international study group. J Clin Oncol 19:2647-2657 